\title{
Watching the dynamics of electrons and atoms at work in solar energy conversion
}

\author{
S. E. Canton, ${ }^{\star a b}$ X. Zhang, ${ }^{C}$ Y. Liu, ${ }^{d}$ J. Zhang, ${ }^{e}$ M. Pápai, ${ }^{\dagger}$ A. Corani, ${ }^{9}$ \\ A. L. Smeigh, ${ }^{h}$ G. Smolentsev, ${ }^{i}$ K. Attenkofer, ${ }^{j}$ G. Jennings, ${ }^{c}$ C. A. Kurtz, ${ }^{c}$ \\ F. Li, ${ }^{k}$ T. Harlang, ${ }^{9}$ D. Vithanage, ${ }^{9}$ P. Chabera, ${ }^{9}$ A. Bordage, ${ }^{\prime}$ L. Sun, ${ }^{m}$ \\ S. Ott, ${ }^{\text {h K. Wärnmark }}{ }^{d}$ and V. Sundström ${ }^{g}$
}

Received 19th May 2015, Accepted 6th July 2015

DOI: $10.1039 / c 5 f d 00084 j$

The photochemical reactions performed by transition metal complexes have been proposed as viable routes towards solar energy conversion and storage into other forms that can be conveniently used in our everyday applications. In order to develop efficient materials, it is necessary to identify, characterize and optimize the elementary steps of the entire process on the atomic scale. To this end, we have studied the photoinduced electronic and structural dynamics in two heterobimetallic ruthenium-cobalt dyads, which belong to the large family of donor-bridge-acceptor systems. Using a combination of ultrafast optical and X-ray absorption spectroscopies, we can clock the light-driven electron transfer processes with element and spin sensitivity. In addition, the changes in local structure around the two metal centers are monitored. These experiments show that the nature of the connecting bridge is decisive for controlling the forward and the backward electron transfer rates, a result supported by quantum chemistry calculations. More generally, this work illustrates how ultrafast optical and X-ray

${ }^{a}$ IFG Structural Dynamics of (Bio)chemical Systems, Max Planck Institute for Biophysical Chemistry, Am Fassberg 11, D-37077 Goettingen, Germany. E-mail: sophie.canton@desy.de

${ }^{b}$ FS-SCS, Structural Dynamics with Ultra-short Pulsed X-rays, Deutsches Elektronensynchrotron DESY, Notkestrasse 85, D-22607 Hamburg, Germany

${ }^{c} X$-ray Sciences Division, Argonne National Laboratory, 9700 South Cass Avenue, Argonne, Illinois 60439, USA ${ }^{d}$ Department of Chemistry, Centre for Analysis and Synthesis, Lund University, S-22100 Lund, Sweden ${ }^{e}$ School of Environmental and Chemical Engineering, Tianjin Polytechnic University, Tianjin 300387, China ${ }^{f}$ Wigner Research Centre for Physics, Hungarian Academy Sciences, PO Box 49, H-1525 Budapest, Hungary ${ }^{g}$ Department of Chemical Physics, Lund University, PO Box 124, S-22100 Lund, Sweden ${ }^{h}$ Department of Chemistry-Ångström Laboratory, Uppsala University, Box 523, S-75120 Uppsala, Sweden ${ }^{i}$ Paul Scherrer Institute, Villigen 5232, Switzerland

${ }^{j}$ Photon Science Directorate, Brookhaven National Laboratory, Upton, New York 11973-5000, USA ${ }^{k}$ State Key Laboratory of Fine Chemicals, Dalian University of Technology, Dalian 116024, China 'Institut de Chimie Moléculaire et des Matériaux d'Orsay, Université Paris-Sud, UMR CNRS 8182, 15 rue Georges Clémenceau, 91405 Orsay Cedex, France

${ }^{m}$ Department of Chemistry, School of Chemical Science and Engineering, KTH Royal Institute of Technology, 10044 Stockholm, Sweden 
techniques can disentangle the influence of spin, electronic and nuclear factors on the intramolecular electron transfer process. Finally, some implications for further improving the design of bridged sensitizer-catalysts utilizing the presented methodology are outlined.

\section{Introduction}

Sunlight, which can be transformed into heat, fuel or electricity, holds great promise as an abundant source of clean and renewable energy. ${ }^{1}$ However, more efficient conversion schemes have yet to be elaborated before this alternative can be pursued as an economically-viable route. ${ }^{2,3}$ In order to increase the photoconversion yields achieved with current artificial molecular devices, it is necessary to identify, characterize and optimize each of the elementary steps involved in the process. As such, investigating the photoinitiated dynamics in rationally-designed donor-bridge-acceptor systems down to the atomic level constitutes an important stepping-stone towards harnessing more complex functional assemblies. ${ }^{4-6}$ The experimental challenge of describing the correlated electronic and structural dynamics on the ultrafast timescale has been tackled so far mainly by optical spectroscopies. ${ }^{7-10}$ These techniques can unravel those of the participating transitions that are allowed by the dipole selection rules. In several instances, such information has been complemented by vibrational spectroscopies ${ }^{\mathbf{1 1}}$ able to track specific modes involving e.g. NO, CO or CN groups. ${ }^{12-16}$ Nevertheless, the need for monitoring directly and simultaneously the coupled evolution of spins, electrons and nuclei during photoconversion continues to drive the development of complementary methodologies. X-ray absorption spectroscopy (XAS) is routinely employed to interrogate, in any state of matter, the bonding environment around a particular atomic centre, e.g. oxidation state, coordination geometry and number of nearest neighbours. This powerful analytical tool has reached the picosecond and femtosecond temporal resolution over the last decade at storage rings ${ }^{17-22}$ and X-ray free electron $\operatorname{laser}^{23,24}$ facilities, as well as in the laboratory with novel generations of table-top X-ray plasma sources. ${ }^{25-30}$ It can now be applied to probe in real time the intramolecular electron transfer and the atomic rearrangements that take place within photoexcited donor-bridge-acceptor systems. The present work focuses on two heterobimetallic ruthenium $(\mathrm{Ru})$-cobalt $(\mathrm{Co})$ complexes that belong to the so-called "weakly-coupled" family, where the donor and the acceptor retain their intrinsic electronic ground-state properties after being linked. The dyads solely differ through the chemical nature of their respective covalent bridges (flexible versus rigid). Synchrotron-based transient XAS at the $\mathrm{Ru}$ and Co $\mathrm{K}$ edges is employed to clock the photoinduced electron transfer process, from the onset of charge separation to the completion of charge recombination. In addition, the local changes in electronic and geometric structure of the transiently-oxidized donor and transiently-reduced acceptor are retrieved. The interpretation is supported by DFT and TD-DFT calculations. Finally, some implications for advanced studies of intramolecular photochemical molecular devices using ultrafast X-ray techniques are outlined. 


\section{Experimental}

\subsection{Synthetic procedures}

General. All chemicals were used as received from commercial sources without further purification. Pre-coated Merck silica gel 60 F254 plates were used for TLC analysis. NMR spectra were recorded on a Bruker Avance 400 NMR spectrometer. Chemical shifts $(\delta)$ are reported relative to shift-scale calibrated with the residual NMR solvent peak $\mathrm{CD}_{3} \mathrm{CN}$ (1.94 ppm for ${ }^{1} \mathrm{H}$ NMR). Elemental analyses were performed by Mikroanalytisches Laboratorium Kolbe (Germany).

In the course of this work, novel synthesis protocols were successfully developed in order to improve the yield of pure product as compared to the ones originally published..$^{31,32}$ The first dyad is based on the building blocks $\left[(\mathrm{bpy})_{2} \mathrm{Co}^{\mathrm{III}}(\mathrm{OTf})_{2}\right](\mathrm{OTf})$ and $\left[(\mathrm{bpy})_{2} \mathrm{Ru}^{\mathrm{II}}(\mathrm{b})-(\mathrm{b})\right]\left(\mathrm{PF}_{6}\right)_{2}$ (denoted $\left[\mathrm{Ru}^{\mathrm{II}} \sim\right]$ and shown in Fig. 1a), where bpy = 2,2'-bipyridine, (b)-(b) = 1,2-bis(4-methyl-2,2'-bipyridyl-4'-yl) ethane and OTf $=$ trifluoromethanesulfonate). The chemical structure of the resulting $\left[(\mathrm{bpy})_{2} \mathrm{Ru}^{\mathrm{II}}(\mathrm{b})-(\mathrm{b}) \mathrm{Co}^{\mathrm{III}}(\mathrm{bpy})_{2}\right]\left(\mathrm{PF}_{6}\right)_{5}$, abbreviated as $\left[\mathbf{R u}^{\mathrm{II}} \sim \mathbf{C o}^{\mathbf{I I I}}\right]$, is given in Fig. 1b. The second dyad is built from $\left[(\mathrm{bpy})_{2} \mathrm{Ru}^{\mathrm{II}}(\mathrm{tpphz})\right]\left(\mathrm{PF}_{6}\right)_{2}$ (displayed in Fig. 1c and denoted $\left.\left[\mathbf{R u}{ }^{\mathrm{II}}=\right]\right)$ where $(\mathrm{tpphz})=$ tetrapyrido $\left(3,2-a: 2^{\prime} 3^{\prime}-c: 3^{\prime \prime}, 2^{\prime \prime}-h: 2^{\prime \prime \prime}, 3^{\prime \prime \prime}-j\right)$ phenazine. The chemical structure of the resulting $\left[(\mathrm{bpy})_{2} \mathrm{Ru}^{\mathrm{II}}(\mathrm{tpphz}) \mathrm{Co}^{\mathrm{III}}(\mathrm{b}-\right.$ py $\left.)_{2}\right]\left(\mathrm{PF}_{6}\right)_{5}$, abbreviated as $\left[\mathbf{R u}^{\mathbf{I I}}=\mathbf{C o}^{\mathrm{III}}\right]$, is given in Fig. $1 \mathrm{~d}$. The very high yield and purity achieved were essential for carrying out the optical and X-ray characterizations described below.

The bridging ligand (b)-(b) was synthesized based on literature methods ${ }^{33,34}$ except for using $\mathrm{CHCl}_{3} / \mathrm{MeOH}(98: 2)$ as the eluent for silica gel chromatography.

$\left[(\mathbf{b p y})_{2} \mathbf{R u}{ }^{\mathbf{I I}}(\mathbf{b})-(\mathbf{b})\right]\left(\mathbf{P F}_{\mathbf{6}}\right)_{2}$. $\mathrm{Ru}(\mathrm{bpy})_{2} \mathrm{Cl}_{2}(361 \mathrm{mg}, 0.68 \mathrm{mmol})$, which was synthesized according to the literature method, ${ }^{35}$ was dissolved in EtOH $(150 \mathrm{~mL})$ and dropped into the refluxing EtOH ( $450 \mathrm{~mL}$ ) solution of (b)-(b) over a period of $1.5 \mathrm{~h}$. The resulting solution was further refluxed for $30 \mathrm{~min}$ and cooled down to RT. The

(a)

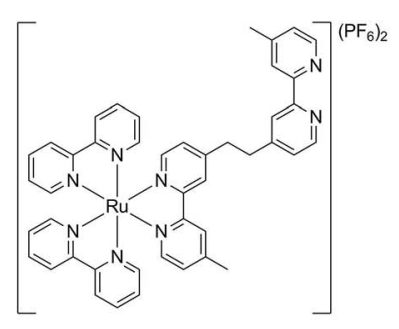

(c)

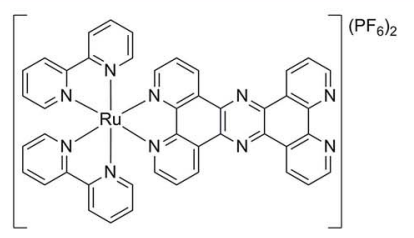

(b)

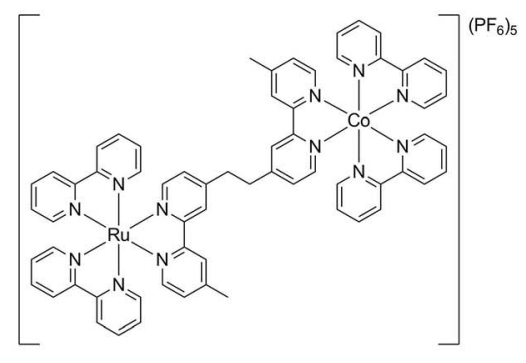

(d)

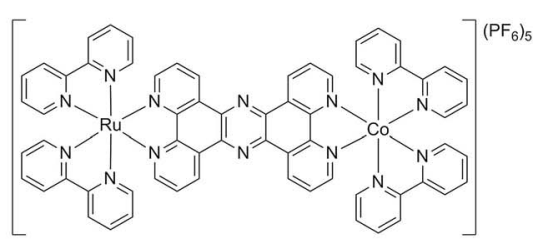

Fig. 1 Chemical structures of the 4 molecules studied in this work: (a) [Ru" $\backsim$ ], (b) $\left[\mathrm{Ru}^{\prime \prime} \sim \mathrm{Co}^{\prime \prime \prime}\right]$, (c) $\left[\mathrm{Ru}^{\prime \prime}=\right]$ and (d) $\left[\mathrm{Ru}^{\prime \prime}=\mathrm{Co}^{\prime \prime \prime}\right]$ (see main text for the definition of the abbreviations). 
solvent was then completely removed and the residue was partitioned with $\mathrm{CHCl}_{3}$ $(100 \mathrm{~mL})$ and distilled water $(15 \mathrm{~mL})$. To the aqueous phase was added an excess amount of solid $\mathrm{NH}_{4} \mathrm{PF}_{6}$ and the precipitates were collected and subjected to size exclusion chromatography $(\phi 5 \mathrm{~cm}, L 150 \mathrm{~cm})$ using BioBeads $\mathrm{S}-\mathrm{X} 1$ as the stationary phase and $\mathrm{MeCN} /$ toluene (40/60) as the eluent. The main band was collected and re-precipitated over $\mathrm{Et}_{2} \mathrm{O}$ /acetone to give the desired product as an orange solid ( $650 \mathrm{mg}$, yield $89 \%$ based on $\mathrm{Ru}(\mathrm{bpy})_{2} \mathrm{Cl}_{2}$ ). The unreacted (b)-(b) ligand was recovered from the $\mathrm{CHCl}_{3}$ phase. ${ }^{1} \mathrm{H} \mathrm{NMR}\left(400 \mathrm{~Hz}, \mathrm{CD}_{3} \mathrm{CN}\right): \delta 8.52(\mathrm{dd}$, $1 \mathrm{H}), 8.49-8.46(\mathrm{~m}, 4 \mathrm{H}), 8.41(\mathrm{~d}, 1 \mathrm{H}), 8.36(\mathrm{~d}, 1 \mathrm{H}), 8.32(\mathrm{~s}, 1 \mathrm{H}), 8.29(\mathrm{~d}, 1 \mathrm{H}), 8.25(\mathrm{t}$, $1 \mathrm{H}), 8.05-7.99(\mathrm{~m}, 4 \mathrm{H}), 7.7(\mathrm{~m}, 3 \mathrm{H}), 7.64(\mathrm{dd}, 1 \mathrm{H}), 7.54(\mathrm{~d}, 1 \mathrm{H}), 7.51(\mathrm{~d}, 1 \mathrm{H})$, 7.39-7.31 (m, 4H), 7.25-7.2 (m, 4H), 3.21-3.11 (m, 4H), $2.5(\mathrm{~s}, 3 \mathrm{H}), 2.45(\mathrm{~s}, 3 \mathrm{H})$.

$\left[(\mathbf{b p y})_{2} \mathbf{R u}{ }^{\text {II }}(\mathbf{b})-(\mathbf{b}) \mathbf{C o}^{\mathbf{I I}}(\mathbf{b p y})_{2}\right]\left(\mathbf{P F}_{6}\right)_{5}$. This dyad (denoted $\left[\mathbf{R u}^{\mathbf{I I}} \sim \mathbf{C o}^{\mathrm{III}}\right]$ ) was synthesized by mixing $\left[(\mathrm{bpy})_{2} \mathrm{Ru}^{\mathrm{II}}(\mathrm{b})-(\mathrm{b})\right]\left(\mathrm{PF}_{6}\right)_{2}(715 \mathrm{mg}, 0.67 \mathrm{mmol})$ and $\left[(\mathrm{bpy})_{2-}\right.$ $\left.\mathrm{Co}^{\mathrm{III}}(\mathrm{OTf})_{2}\right](\mathrm{OTf})^{36}(732 \mathrm{mg}, 0.8 \mathrm{mmol})$ in $140 \mathrm{~mL}$ of $\mathrm{MeOH} / \mathrm{MeCN}(1 / 1)$ at $50{ }^{\circ} \mathrm{C}$ under $\mathrm{N}_{2}$ for $30 \mathrm{~min}$. After cooling to RT, the solution was concentrated to $c a .10$ $\mathrm{mL}$, to which $50 \mathrm{~mL}$ of distilled water and an excess amount of $\mathrm{NH}_{4} \mathrm{PF}_{6}$ solids were added. The precipitates were collected and subjected to size exclusion chromatography ( $\phi 5 \mathrm{~cm}, L 150 \mathrm{~cm}$ ) using BioBeads S-X1 as the stationary phase and MeCN/toluene (40/60) as the eluent. The main band was collected and re-precipitated over $\mathrm{Et}_{2} \mathrm{O} /$ acetone to give the desired product as an orange solid (1.2 g, yield 95\% based on [(bpy $\left.\left.)_{2} \mathrm{Ru}^{\mathrm{II}}(\mathrm{b})-(\mathrm{b})\right]\left(\mathrm{PF}_{6}\right)_{2}\right) .{ }^{1} \mathrm{H}$ NMR $\left(400 \mathrm{~Hz}, \mathrm{CD}_{3} \mathrm{CN}\right): \delta$ $8.67(\mathrm{~d}, 5 \mathrm{H}), 8.61(\mathrm{~s}, 1 \mathrm{H}), 8.51-8.43(\mathrm{~m}, 10 \mathrm{H}), 8.05(\mathrm{t}, 4 \mathrm{H}), 7.42-7.25(\mathrm{~m}, 10 \mathrm{H}), 7.15$

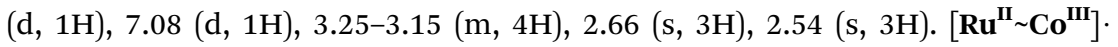
toluene $\left(\mathrm{C}_{71} \mathrm{H}_{62} \mathrm{CoF}_{30} \mathrm{~N}_{12} \mathrm{P}_{5} \mathrm{Ru}\right)$ calc. $\mathrm{C}$ : $43.33 ; \mathrm{H}$ : 3.18 ; N: 8.54; found C: $43.09 ; \mathrm{H}$ : 3.29; N: 8.95. ESI-HRMS $\left\{\left[\mathbf{R u}^{\mathrm{II}} \sim \mathbf{C o}^{\mathrm{III}}\right]-2\left(\mathrm{PF}_{6}\right)\right\}^{2+}$ calc. 793.0948; found 793.0918.

\subsection{Time-resolved optical emission measurements}

The general details of the setup have been reported elsewhere. ${ }^{37}$ A $440 \mathrm{~nm}$ pulsed diode laser head from Picoquant LCH-P-C-440 was used as an excitation source with a $2.5 \mathrm{MHz}$ repetition rate. The average power at the sample was $\sim 50 \mu \mathrm{W}$. Emission was collected at the magic angle $\left(54.7^{\circ}\right)$ above $460 \mathrm{~nm}$, and timeresolved using time correlated single photon counting (TCSPC) detection.

\subsection{Time-resolved optical absorption measurements}

The details of the femtosecond transient absorption spectroscopy setups have been reported for the experiments on the flexible dyad $\left[\mathbf{R u}^{\mathbf{I I}} \backsim \mathbf{C o}^{\mathbf{I I I}}\right]^{38}$ and on the rigid dyad $\left[\mathbf{R u}^{\mathbf{I I}}=\mathbf{C o}^{\mathbf{I I I}}\right] \cdot{ }^{36}$ The excitation wavelengths were chosen respectively as $351 \mathrm{~nm}$ for $\left[\mathbf{R u}^{\mathbf{I I}} \backsim \mathbf{C o}^{\mathbf{I I}}\right]$ and $527 \mathrm{~nm}$ for $\left[\mathbf{R u}^{\mathbf{I I}}=\mathbf{C o} \mathbf{o}^{\mathbf{I I I}}\right]$. Absorption spectra were taken before and after measurements to check for potential sample degradation, and none was observed.

\subsection{Time-resolved X-ray absorption measurements}

Time-resolved X-ray absorption spectra and kinetics with approximately 80 ps temporal resolution were obtained at beamline 11-ID-D of the Advanced Photon Source (Argonne, IL, USA). The details of the setup, the experimental conditions and the data analysis procedure have been reported elsewhere. ${ }^{36}$ Both dyads were dissolved in acetonitrile. The excitation wavelengths were chosen respectively as 
$351 \mathrm{~nm}$ for $\left[\mathbf{R u}^{\mathbf{I I}} \backsim\right]$ and $\left[\mathbf{R u}^{\mathbf{I I}} \backsim \mathbf{C o}^{\mathbf{I I I}}\right]$ (spectra), $527 \mathrm{~nm}$ for $\left[\mathbf{R u}^{\mathbf{I I}} \backsim \mathbf{C o}^{\mathbf{I I I}}\right]$ (kinetics) and $527 \mathrm{~nm}$ for $\left[\mathbf{R u}^{\text {II }}=\mathbf{C o}^{\text {III }}\right]$ (spectra and kinetics).

\subsection{DFT and TD-DFT optimizations}

All calculations were carried out with the ORCA program package. ${ }^{39}$ The geometries of $\left[\mathbf{R u}{ }^{\text {II }} \sim(\mathrm{LS}, S=0)\right],\left[\mathbf{R u}^{\mathrm{II}} \sim \mathbf{C o}^{\mathrm{III}}(\mathrm{LS}, S=0)\right],\left[\mathrm{Ru}^{\mathrm{III}} \sim \mathrm{Co}^{\mathrm{II}}(\mathrm{HS}, S=4)\right]$, $\left[\mathbf{R u}^{\mathrm{II}}=(\mathrm{LS}, S=0)\right],\left[\mathbf{R u}^{\mathrm{II}}=\mathbf{C o} \mathbf{C o}^{\mathrm{III}}(\mathrm{LS}, S=0)\right]$ and $\left[\mathrm{Ru}^{\mathrm{III}}=\mathrm{Co}^{\mathrm{II}}(\mathrm{HS}, S=4)\right]$ (where LS and HS denote the low spin and the high spin respectively), were fully optimized with the B3LYP*/TZVP method. This functional has provided satisfactory results for the structures and energetics of the LS and HS states of transition metal complexes. ${ }^{40}$ The conducting-like screening solvation model (COSMO) ${ }^{\mathbf{4 1}}$ was used, by choosing the dielectric constant for acetonitrile $(\varepsilon=36.6)$. The UV/Vis spectra of $\left[\mathbf{R u}^{\mathbf{I I}} \backsim\right]$ and $\left[\mathbf{R u}^{\mathbf{I I}} \sim \mathbf{C o}^{\mathbf{I I I}}\right]$ were obtained by calculating 300 singlet excited states with the time-dependent (TD)-B3LYP*/TZVP method at the equilibrium geometries. In these TD-DFT computations the Tamm-Dancoff approximation (TDA) was applied. ${ }^{42}$ In these cases, the COSMO model was also employed, using acetonitrile as solvent.

\section{Results and discussion}

\subsection{Electronic and geometric structures in the ground state}

The DFT optimized structures of $\left[\mathbf{R u}^{\mathbf{I I}} \backsim\right]\left[\mathbf{R} \mathbf{u}^{\mathbf{I I}} \sim \mathbf{C o}^{\mathbf{I I I}}\right],\left[\mathbf{R} \mathbf{u}^{\mathbf{I I}}=\right]$ and $\left[\mathbf{R} \mathbf{u}^{\mathbf{I I}}=\mathbf{C o} \mathbf{o}^{\mathbf{I I I}}\right]$ in the ground state are displayed respectively in Fig. $2 \mathrm{a}-\mathrm{d}$. In $\left[\mathbf{R u}^{\mathbf{I I}} \sim \mathbf{C o}^{\mathbf{I I I}}\right]$, the flexible saturated alkyl chain allows free rotation around the $\mathrm{C}-\mathrm{C}$ bond. The $\mathrm{Ru}^{\mathrm{II}}$ and $\mathrm{Co}^{\mathrm{III}}$ moieties are held $13.36 \AA$ apart and both metal centres are in their LS state. Steady-state spectroscopy in the UV-visible region provides basic information about the energetics of the system. The absorption spectrum of $\left[\mathbf{R u}^{\mathbf{I I}} \sim \mathbf{C o}^{\mathbf{I I I}}\right]$ dissolved in acetonitrile ( $\mathrm{MeCN})$ is displayed in Fig. 3a. As expected, it coincides with the superposed traces obtained from separated $\left[\mathrm{Ru}^{\mathrm{II}}(\mathrm{bpy})_{3}\right]$ and $\left[\mathrm{Co}^{\mathrm{III}}(\mathrm{bpy})_{3}\right]$,

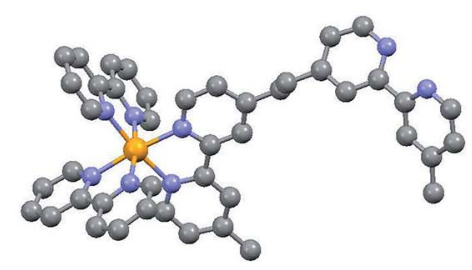

(a)

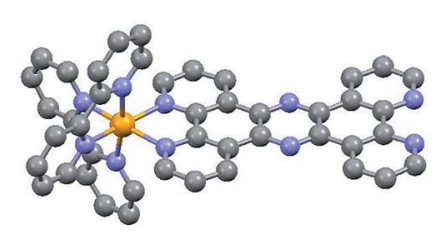

(c) (b)
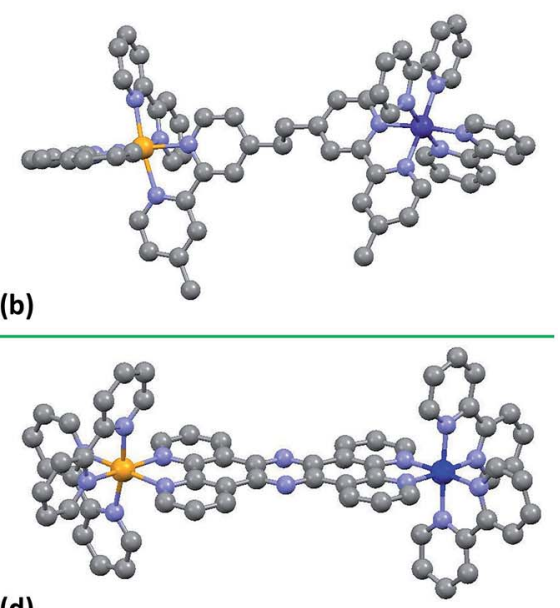

(d)

Fig. 2 Optimized DFT structures of (a) $\left[\mathrm{Ru}^{\prime \prime} \sim\right]$, (b) $\left[\mathrm{Ru}^{\prime \prime} \sim \mathrm{Co}^{\prime \prime \prime}\right]$, (c) $\left[\mathrm{Ru} \mathrm{u}^{\prime \prime}=\right]$ and (d) $\left[\mathrm{Ru}^{\prime \prime}=\mathrm{Co}^{\mathrm{III}}\right]$. The $\mathrm{H}$ atoms have been omitted for clarity. 


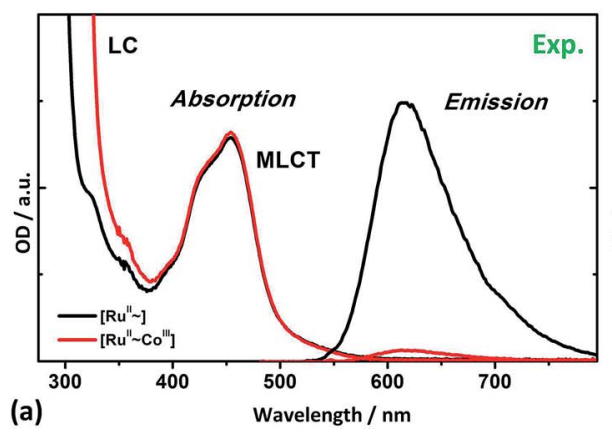

Paper

Fig. 3 (a) UV-visible absorption and emission (450 nm excitation wavelength) spectra of $\left[\mathrm{Ru}^{\prime \prime} \sim\right]$ and $\left[\mathrm{Ru}^{\prime \prime} \sim \mathrm{Co}^{\prime \prime \prime}\right]$ in MeCN. (b) Absorption spectrum of $\left[\mathrm{Ru}^{\prime \prime} \backsim\right]$ and $\left[\mathrm{Ru}^{\prime \prime} \sim \mathrm{Co} \mathrm{O}^{\mathrm{II}}\right]$ in $\mathrm{MeCN}$ from TD-DFT calculations.

since the absence of conjugation within the bridge precludes any electronic communication. The $\pi \pi^{*}$ ligand centred (LC) transitions are found below 350 $\mathrm{nm}$, while the singlet metal to ligand charge transfer band $\left({ }^{1} \mathrm{MLCT}\right)$ is located around $450 \mathrm{~nm}$. The absorption in the visible is thus solely due to the $\mathrm{Ru}^{\mathrm{II}}$ unit. The spectral shapes for $\left[\mathbf{R u}^{\mathbf{I I}} \backsim\right]$ and $\left[\mathbf{R u}^{\mathbf{I I}} \sim \mathbf{C o}^{\mathbf{I I I}}\right]$ in MeCN are well reproduced by the TD-DFT calculations (Fig. $3 \mathrm{~b}$ ). The emission spectrum of $\left[\mathbf{R} \mathbf{u}^{\mathbf{I I}} \backsim\right]$ centred at $620 \mathrm{~nm}$ (shown in Fig. 3a) resembles that from ${ }^{3}$ MLCT $\left[\mathrm{Ru}(\mathrm{bpy})_{3}\right]^{2+*} .^{43}$ Linking the $\mathrm{Co}^{\text {III }}$ moiety in $\left[\mathbf{R u}^{\text {II }} \sim \mathbf{C o}^{\text {III }}\right]$ strongly quenches more than $95 \%$ of the phosphorescence with respect to a solution of $\left[\mathbf{R u}^{\text {II }} \sim\right.$ ] having the same optical density (Fig. 3a, where the excitation wavelength was $450 \mathrm{~nm}$ ). In $\left[\mathbf{R u}^{\mathbf{I I}}=\mathbf{C o}{ }^{\mathrm{III}}\right]$, the $\mathrm{Ru}^{\mathrm{II}}$ and $\mathrm{Co}^{\mathrm{III}}$ centres are held rigidly $12.77 \AA$ apart with fixed orientation through the large conjugated planar $\pi$ system. The UV-vis spectrum of $\left[\mathbf{R u}^{\mathbf{I I}}=\right]$ in $\mathrm{MeCN}$ is displayed in Fig. 4a. The regions between $340-380 \mathrm{~nm}, 400-440 \mathrm{~nm}$ and 440-550 nm are assigned respectively to tpphz LC, ${ }^{1} \mathrm{MLCT} \mathrm{Ru}{ }^{\mathrm{II}} \rightarrow$ bpy and ${ }^{1} \mathrm{MLCT}$ $\mathrm{Ru}^{\mathrm{II}} \rightarrow \mathrm{tpphz}_{\text {phen }}$ transitions. In other words, the light-harvesting chromophore should be seen as a heteroleptic Ru complex, with the tpphz bridge playing the role of an extended ligand. Upon coordination to the $\mathrm{Co}^{\mathrm{III}}$ moiety, the absorbance
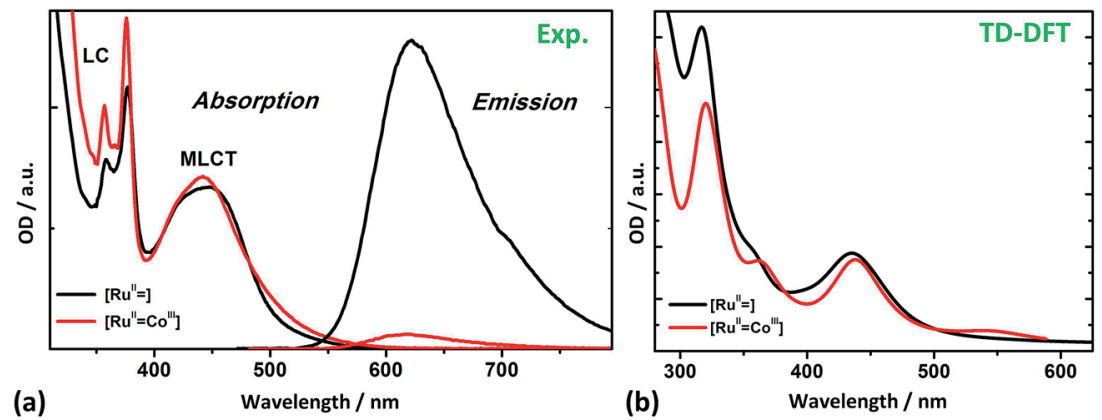

Fig. 4 (a) UV-visible absorption and emission (450 nm excitation wavelength) spectra of $\left[\mathrm{Ru}^{\prime \prime}=\right]$ and $\left[\mathrm{Ru}^{\prime \prime}=\mathrm{Co}^{\prime \prime \prime}\right]$ in MeCN. (b) Absorption spectrum of $\left[\mathrm{Ru}^{\prime \prime}=\right]$ and $\left[\mathrm{Ru}^{\prime \prime}=\mathrm{Co} \mathrm{O}^{\prime \prime \prime}\right]$ in $\mathrm{MeCN}$ from TD-DFT calculations. 
is only slightly modified by the interaction of the metal with the distal bpy of tpphz. Therefore, this dyad also belongs to the "weakly-coupled" family and the absorption in the visible solely originates from the $\mathrm{Ru}^{\mathrm{II}}$ unit. The spectral shapes are well reproduced by the TD-DFT calculations for $\left[\mathbf{R u}{ }^{\mathbf{I I}}=\right]$ and $\left[\mathbf{R u ^ { I I }}=\mathbf{C o}^{\mathbf{I I I}}\right]$ in MeCN (Fig. 4b). The pronounced emission from ${ }^{3} \mathrm{MLCT}\left(\mathrm{Ru}-\mathrm{tpphz} \mathrm{phen}_{\mathrm{n}}\right)$ is centred around $627 \mathrm{~nm} .{ }^{44}$ For $\left[\mathbf{R u}^{\mathrm{II}}=\mathbf{C o}{ }^{\mathrm{III}}\right], 95 \%$ of the phosphorescence is quenched with respect to a solution of $\left[\mathbf{R u}^{\mathrm{II}}=\right]$ having the same optical density (Fig. $4 \mathrm{a}$, where the excitation wavelength was $450 \mathrm{~nm}$ ).

To summarize, coordination of a $\mathrm{Co}^{\mathrm{III}}$ coordination centre at the open site suppresses the emission from the photoexcited Ru chromophore through energy or electron transfer for both dyads. Since the absorption and emission bands do not overlap, Förster energy transfer can be ruled out. In addition, the two Ru-Co separations are too large to enable Dexter energy transfer. Therefore, electron transfer, which is thermodynamically allowed, can be proposed as deactivation mechanism. This aspect is investigated with ultrafast optical methods as described below.

\subsection{Photoinduced dynamics monitored with time-resolved optical spectroscopies}

The lifetimes of the two isolated Ru complexes $\left[\mathbf{R} \mathbf{u}^{\mathbf{I I}} \backsim\right]$ and $\left[\mathbf{R} \mathbf{u}^{\mathbf{I I}}=\right]$ in $\mathrm{MeCN}$ at room temperature are extracted from the single-exponential fit of the timeresolved optical emission measurements shown in Fig. 5a. They are respectively $135 \pm 10 \mathrm{~ns}$ for $\left[\mathbf{R u}^{\mathbf{I I}} \sim\right]$ and $150 \pm 10 \mathrm{~ns}$ for $\left[\mathbf{R u}^{\mathbf{I I}}=\right]$, both much shorter than the ones reported for $\left[\mathrm{Ru}^{\mathrm{II}}(\mathrm{bpy})_{3}\right](\sim 1.1 \mu \mathrm{s})^{43}$ and $\left.\left[\mathrm{Ru}^{\mathrm{II}} \text { (phen }\right)_{3}\right](\sim 500 \mathrm{~ns}) .{ }^{45}$ In the two dyads, the emission intensity is drastically reduced (Fig. 5b), reflecting the quenching of the photoexcited $\mathrm{Ru}^{\mathrm{II} *}$, as expected from the steady-state measurements. The dynamics of the remnant emission closely resembles the ones observed in the isolated $\left[\mathbf{R u} \mathbf{u}^{\mathbf{I I}} \backsim\right]$ and $\left[\mathbf{R} \mathbf{u}^{\mathbf{I I}}=\right]$ complexes, suggesting parallel deactivation pathways (e.g. interligand electron transfer). Further information about the excited states involved in the dynamics can be obtained through transient optical absorption measurements. Fig. 6a displays the temporal evolution of the band centred at $\sim 360 \mathrm{~nm}$ ascribed to reduced bpy, which is formed quasi-instantaneously upon femtosecond laser excitation of $\left[\mathbf{R u}^{\mathbf{I I}} \sim \mathbf{C o}^{\mathbf{I I}}\right]$ at
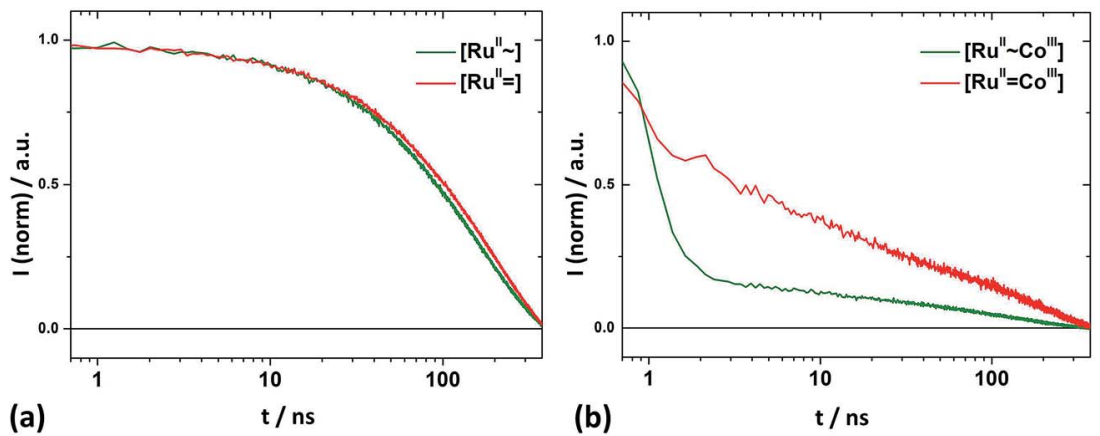

Fig. 5 (a) Time-resolved emission spectra of $\left[R u^{\prime \prime} \sim\right]$ (green) and $\left[R u^{\prime \prime}=\right]$ (red), and (b) of $\left[\mathrm{Ru}^{\prime \prime} \sim \mathrm{Co}^{\prime \prime \prime}\right]$ (green) and $\left[\mathrm{Ru}^{\prime \prime}=\mathrm{Co}^{\prime \prime \prime}\right]$ (red) in $\mathrm{MeCN}$. 


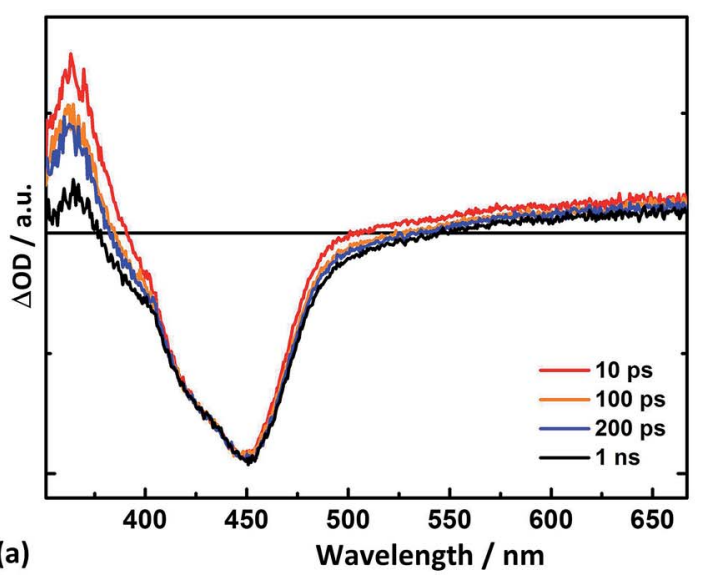

Paper

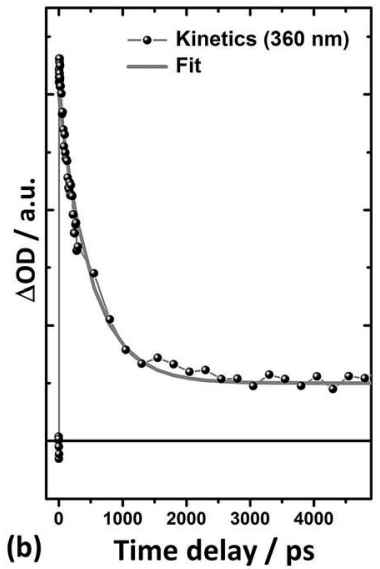

Fig. 6 (a) Time-resolved optical absorption spectra at selected pump-probe time delays and (b) kinetics at $360 \mathrm{~nm}$ (grey) with single-exponential fit (light grey) for [Ru" $\left.\backsim \mathrm{Co}^{\prime \prime \prime}\right]$ in $\mathrm{MeCN}$. The excitation wavelength was $351 \mathrm{~nm}$.

$351 \mathrm{~nm}$. It decays with a $\sim 330 \pm 20$ ps lifetime (Fig. 6b). The long time scale component, which does not decay on the few ns time scale covered by the delay line, is related to the surviving ${ }^{3} \mathrm{MLCT}$ of $\mathrm{Ru}^{\mathrm{II} *}$. It should be noted that this channel is also evidenced in the steady state and time-resolved optical emission experiments as residual emission (Fig. 4a) and a long-lived component respectively (Fig. 5b). For $\left[\mathbf{R u}{ }^{\mathbf{I I}}=\mathbf{C o}^{\mathbf{I I I}}\right]$, in contrast, a broad band with a maximum at $\sim 625 \mathrm{~nm}$ appears quasi-instantaneously following femtosecond laser excitation at $527 \mathrm{~nm}$ (Fig. 7a). This is the signature of reduced pyrazine, the central part of the tpphz ligand. ${ }^{46,47}$ This feature decays rapidly over $\sim 0.5$ ps (Fig. 7b), showing that the electron leaves the pyrazine on the sub-picosecond time scale. It should be pointed out here that the kinetics acquired at $580 \mathrm{~nm}$ for photoexcited
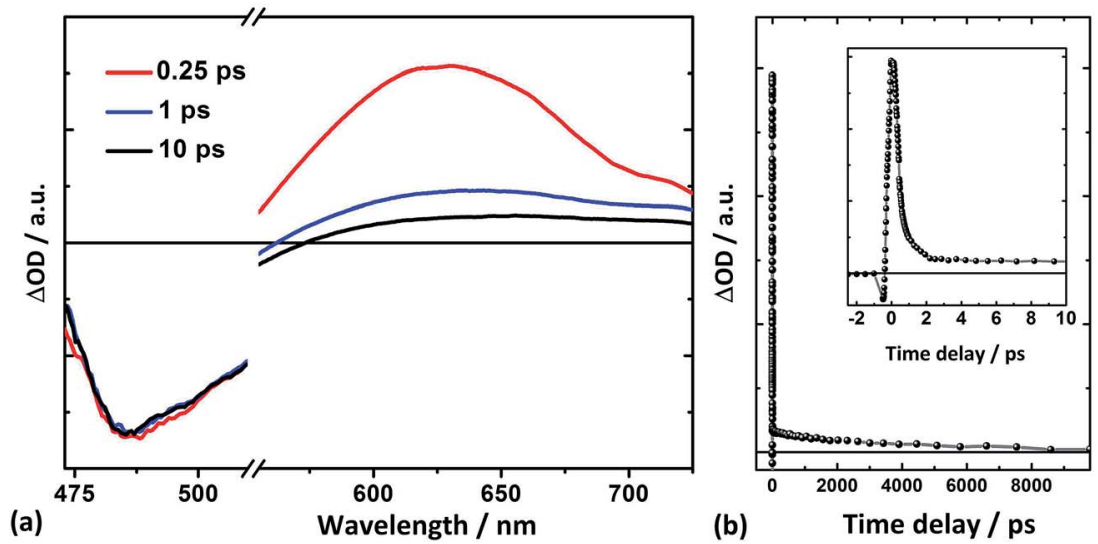

Fig. 7 (a) Time-resolved optical absorption spectra at selected pump-probe time delays and (b) kinetics acquired at $580 \mathrm{~nm}$ for $\left[\mathrm{Ru}^{\prime \prime}=\mathrm{Co}^{\prime \prime \prime}\right]$ in $\mathrm{MeCN}$. The excitation wavelength was $527 \mathrm{~nm}$. 
$\left[\mathbf{R} \mathbf{u}^{\mathbf{I I}}=\mathbf{C o} \mathbf{o}^{\mathrm{III}}\right]$ cannot be described by a single-exponential decay (inset of Fig. $7 \mathrm{~b}$ ), suggesting that the deactivation proceeds out of equilibrium. ${ }^{48}$ The optical spectroscopic tools employed so far have delivered diagnostics about the multiple time scales that describe the quenching of the initial excitation through electron transfer. However, no direct information about the electronic and geometric structure of the charge-separated species can be extracted. Time-resolved XAS at the $\mathrm{Ru}$ and at the Co K edge provides supplementary insight into the dynamical evolution of the two systems, as described below.

\subsection{Photoinduced dynamics monitored with time-resolved X-ray absorption spectroscopy}

Fig. 8a displays the normalized X-ray absorption coefficient $\mu$ as a function of incident X-ray photon energy $E$ at the Ru K edge $(22.1 \mathrm{keV})$ acquired without laser excitation $\left(\mu_{\text {laser_ofF }}\right.$, black $)$ and at $\Delta t=400 \mathrm{ps}$ ( $\mu_{\text {laser_oN }}$, orange), where $\Delta t$ is the time delay between the optical pump and the X-ray probe for $\left[\mathbf{R u}^{\mathbf{I}} \backsim \mathbf{C o}^{\mathbf{I I I}}\right]$. Fig. 8b displays the difference $\left[\mu_{\text {laser_on }}-\mu_{\text {laser_ofF }}\right]$, which reveals the spectral contribution from the fraction $\alpha_{\mathrm{Ru}}$ of excited species (green). The absence of signal at $\Delta t$ $<0$ (grey) with laser illumination confirms that the transient at $\Delta t=400 \mathrm{ps}$ is photoinduced. A reference (black) is constructed by subtracting the normalized steady-state $\mu$ of $\left[\mathrm{Ru}^{\mathrm{III}}(\mathrm{bpy})_{3}\right]\left(\mathrm{ClO}_{4}\right)_{3}$ from that of $\left[\mathrm{Ru}^{\mathrm{II}}(\mathrm{bpy})_{3}\right](\mathrm{Cl})_{2}$ powders. This trace approximates the profile that would stem from a complete oxidation of all the $\mathrm{Ru}^{\mathrm{II}}$ centres to $\mathrm{Ru}$ III within the probed volume (i.e. $\alpha_{\mathrm{Ru}}=100 \%$ ). Comparison with the transient spectrum shows good agreement. The resemblance with the derivative $-\mathrm{d} \mu / \mathrm{d} E$ of the $\mu_{\text {laser_off }}$ spectrum for $\left[\mathbf{R u}^{\text {II }} \sim \mathbf{C o}^{\text {III }}\right]$ (red) evidences that the spectral shape is largely dominated by the effects of an edge shift. This is consistent with the known effect of a change in formal oxidation number. The
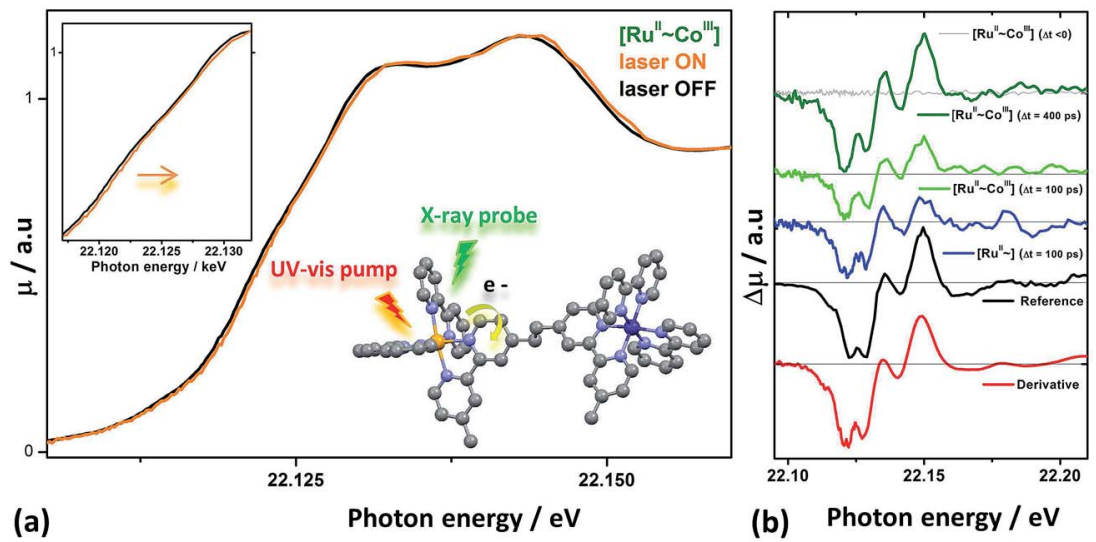

Fig. 8 (a) Transient $\mathrm{X}$-ray absorption spectra at the Ru K edge: ground state spectrum, $\mu_{\text {laser_OFF, }}$ and $\Delta t=400 \mathrm{ps}$ after laser excitation, $\mu_{\text {laser_ON, (orange) for }\left[\mathrm{Ru}^{\prime \prime} \sim \mathrm{CO}^{\prime \prime \prime}\right] \text { in }}$ $\mathrm{MeCN}$. The arrow indicates the direction of the edge shift. (b) From top to bottom, difference signal [ $\left.\mu_{\text {laser_ON }}-\mu_{\text {laser_OFF }}\right]$ for $\Delta t<0$ (grey), at $\Delta t=400$ ps (green), at $\Delta t=100$ ps (light green) for [Ru" $\sim$ Coll'] in $\mathrm{MeCN}$, at $\Delta t=$ for 100 ps (blue) for $\left[\mathrm{Ru}^{\prime \prime} \sim\right]$ in $\mathrm{MeCN}$, reference signal (black) and scaled derivative of the $\mu_{\text {laser_ofF spectrum for }\left[\mathrm{Ru}^{\prime \prime} \sim \mathrm{Co}^{\prime \prime \prime}\right]}$ ] (red) as described in the text. The excitation wavelength was $351 \mathrm{~nm}$ for [Ru" $\sim$ ] and $\left[\mathrm{Ru}^{\prime \prime} \sim \mathrm{Co}^{\prime \prime \prime}\right]$. 
small difference in the white line region could be attributed to the interaction with the counterions in the powder phase. The reference also allows estimating $\alpha_{\mathrm{Ru}} \sim 35 \%$ for the excited state population by direct scaling. It should be noted that the transient spectrum is indistinguishable from the population of the ${ }^{3}$ MLCT in the $\left[\mathbf{R u}^{\mathrm{II}} \sim\right.$ ] that moves some of the $\mathrm{Ru}^{\mathrm{II}} 5 \mathrm{~d}$ electron density onto the bpy ligand, (blue), therefore the Ru K edge XANES cannot readily distinguish between MLCT excitation and formal oxidation that both involve the outermost metal electron. Nevertheless, the amplitude of the transient X-ray signal increases between 100 ps (light green) and 400 ps (green) for $\left[\mathbf{R u}^{\mathbf{I I}} \sim \mathbf{C} \mathbf{o}^{\mathrm{III}}\right]$, confirming that electron transfer takes place. On the other hand, the transient signal of photoexcited $\left[\mathbf{R} \mathbf{u}^{\mathbf{I I}} \backsim\right]$ is almost constant over that temporal window.

Fig. 9a displays the normalized X-ray absorption coefficient $\mu_{\text {laser_ofF }}$ (black) as a function of incident X-ray photon energy $E$ at the Co K edge $(7709 \mathrm{eV})$ for $\left[\mathbf{R u} \mathbf{I I}^{\mathbf{I I}} \sim \mathbf{C o}^{\text {III }}\right]$. The interpretation of the pre-edge and XANES regions can be achieved based on a simple molecular orbital description in terms of $(n, l)$ atomic orbital. ${ }^{49}$ In the molecular ground state, the $\mathrm{Co}^{\mathrm{III}}$ center has an octahedral $\left(\mathrm{O}_{\mathrm{h}}\right)$ coordination and $\mathrm{a}\left(\mathrm{t}_{2 \mathrm{~g}}\right)^{6}$ LS configuration. The weak pre-edge intensity $(\mathrm{P}$, inset of Fig. 9a) is assigned to the $1 \mathrm{~s} \rightarrow 3 \mathrm{~d}\left(\mathrm{e}_{\mathrm{g}}\right)$ transition, which is dipole forbidden in a centrosymmetric environment $(\Delta l=2)$, but quadrupole allowed. It can also acquire intensity through distortion that causes $3 \mathrm{~d}-4 \mathrm{p}$ mixing upon symmetry lowering. ${ }^{49}$ The XANES features originate from transitions of the $1 \mathrm{~s}$ core electron to the unoccupied states that are built from mixing the metal $4 \mathrm{p}$ orbital with the symmetry adapted combinations of ligand orbitals. ${ }^{36}$ Features $\mathrm{A}$ and $\mathrm{B}$ are ascribed to the dipole allowed promotion of a 1s core electron to the $\operatorname{Co}(4 \mathrm{p})-\mathrm{N}(2 \mathrm{p})$ hybridized state. Feature $\mathrm{C}$ arises from multiple scattering. Feature D corresponds to single scattering of the outgoing photoelectron by the 6 nearest neighbour $\mathrm{N}$ atoms so that its energy position satisfies Natoli's rule. ${ }^{50}$
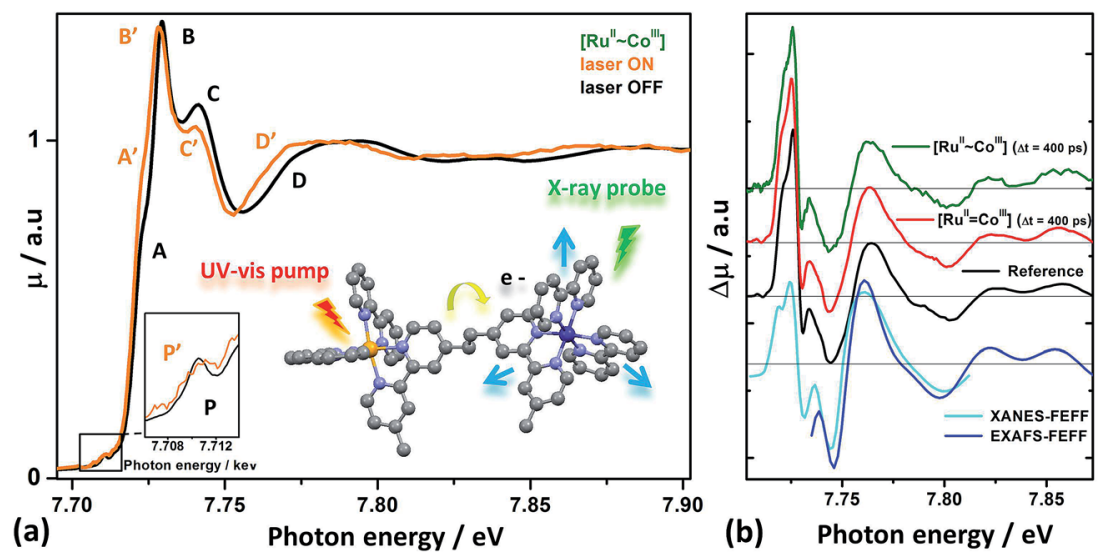

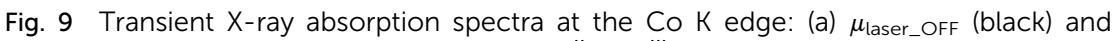
$\mu_{\text {laser_on }}$ (orange) signal at $\Delta t=400 \mathrm{ps}$ for $\left[\mathrm{Ru}^{\prime \prime} \sim \mathrm{Co}^{\prime \prime \prime}\right]$ in $\mathrm{MeCN}$. The inset shows the preedge region. (b) (top) Difference signal $\left[\mu_{\text {laser_on }}-\mu_{\text {laser_OfF }}\right]$ at $\Delta t=400$ ps for $\left[\mathrm{Ru}^{\prime \prime} \backsim \mathrm{Co}^{\mathrm{III}}\right]$ (green), $\left[\mathrm{Ru}^{\prime \prime}=\mathrm{Co}^{\mathrm{III}}\right]$ (red) in $\mathrm{MeCN}$ after rescaling to the reference trace (black) ${ }^{29}$ described in the text, XANES (cyan) and EXAFS (blue) profiles obtained from FEFF9.0 simulations based on the optimized DFT structures of $\left[\mathrm{Ru}^{\prime \prime}=\mathrm{Co}^{\mathrm{III}}\right]$ and $\left[\mathrm{Ru}^{\mathrm{III}}=\mathrm{CO}^{\prime \prime}(\mathrm{HS})\right]$. The excitation wavelength was $351 \mathrm{~nm}$ for [Ru" $\left.\sim \mathrm{Co}^{\prime \prime \prime}\right]$ and $527 \mathrm{~nm}$ for $\left[\mathrm{Ru}^{\prime \prime}=\mathrm{Co}^{\prime \prime \prime}\right]$. 
Upon laser excitation, the spectral fingerprints change drastically for $\mu_{\text {laser_ON }}$ as shown in Fig. 9a for $\Delta t=400$ ps (orange). Fig. 9b presents the $\left[\mu_{\text {laser_ON }}-\mu_{\text {laser_OFF }}\right]$ of $\left[\mathbf{R u}^{\mathbf{I I}} \sim \mathbf{C o}^{\mathbf{I I I}}\right]$ (green) and $\left[\mathbf{R} \mathbf{u}^{\mathbf{I I}}=\mathbf{C o} \mathbf{o}^{\mathbf{I I I}}\right]$ (red) at $\Delta t=400$ ps. A reference (black) is constructed by subtracting the normalized steady-state $\mu$ of $\left[\mathrm{Co}^{\mathrm{III}}(\mathrm{bpy})_{3}\right]\left(\mathrm{PF}_{6}\right)_{3}$ in the $\left(\mathrm{t}_{2 \mathrm{~g}}\right)^{6}$ LS state and $\left[\mathrm{Co}^{\mathrm{II}}(\mathrm{bpy})_{3}\right]\left(\mathrm{PF}_{6}\right)_{2}$ in the $\left(\mathrm{t}_{2 \mathrm{~g}}\right)^{5}\left(\mathrm{e}_{\mathrm{g}}\right)^{2}$ $\mathrm{HS}$, both dissolved in MeCN. This trace reproduces the details of the transient signals, and it is very well modelled with XANES (cyan) and EXAFS (blue) FEFF9.0 simulations based on the optimized DFT structures. Through direct scaling, it is also possible to infer an excited population $\alpha_{\mathrm{Co}}$ of $\sim 65 \%$ for $\left[\mathbf{R u}{ }^{\text {II }}=\mathbf{C o}{ }^{\text {III }}\right]$ and of $\sim 30 \%$ for $\left[\mathbf{R u} \mathbf{u}^{\text {II }} \sim \mathbf{C o}^{\text {III }}\right]$, this latter value being in very good agreement with the $\alpha_{\mathrm{Ru}}$ estimated from the measurements at the Ru K edge. These findings confirm that the transient spectra of $\left[\mathbf{R u}^{\mathbf{I I}} \backsim \mathbf{C o}^{\mathrm{III}}\right]$ and $\left[\mathbf{R u}^{\mathrm{II}}=\mathbf{C o}^{\mathrm{III}}\right]$ are monitoring a $\mathrm{Co}^{\mathrm{III}}$ to $\mathrm{Co}^{\mathrm{II}}$ photoinduced reduction accompanied by a change of spin from LS to HS. ${ }^{51}$ More specifically, the pre-edge feature $\left(\mathrm{P}^{\prime}\right.$, inset of Fig. 9a) splits into the unresolved multiplets of $1 \mathrm{~s} \rightarrow 3 \mathrm{~d}\left(\mathrm{t}_{2 \mathrm{~g}}\right)$ and $1 \mathrm{~s}$ $\rightarrow 3 \mathrm{~d}\left(\mathrm{e}_{\mathrm{g}}\right)$ of the ${ }^{4} \mathrm{Co}^{\mathrm{II}}$ (HS) moiety. The addition of an electron with the concurrent promotion of a slightly bonding $t_{2 g}$ electron into the antibonding $\mathrm{e}_{\mathrm{g}}$ level weakens the strength of the metal-ligand interaction, causing an average bond elongation $\Delta R$ of $\sim 0.2 \AA .^{52-54}$ This is reflected in the shift of $\mathrm{D}$ to $\mathrm{D}^{\prime}$ as the first coordination sphere expands. Since the overlap between the $\operatorname{Co}(4 \mathrm{p})$ and the ligand orbitals is diminished, the degree of hybridization decreases and the metal orbitals are stabilized in energy, explaining the trends observed for the photoinduced white line (feature $\mathrm{A}^{\prime}$ and $\mathrm{B}^{\prime}$ ).

To summarize, XAS with $\sim 80 \mathrm{ps}$ temporal resolution at the $\mathrm{Ru}$ and Co K edge captures the photoinduced dynamics in $\left[\mathbf{R u}^{\mathbf{I I}} \sim \mathbf{C o}^{\mathbf{I I I}}\right]$ and $\left[\mathbf{R u}^{\mathbf{I I}}=\mathbf{C o}^{\mathbf{I I I}}\right]$ with element and spin sensitivity. Following the identification of specific spectral fingerprints, quantitative rates of electron transfer can be extracted to complement the optical results, as described below.

\subsection{Comprehensive mapping of the intramolecular charge transfer process}

When the donor and the acceptor are simply mixed in a solution exposed to light, the photoinduced electron transfer rates are governed by the diffusion process, imposing a lower limit of $\sim 10^{-9} \mathrm{~s}$ on the time scales. ${ }^{55}$ Hence the incorporation of a covalent linker is clearly essential for realizing and stabilizing ultrafast charge separation. However, unravelling the exact role played by the bridge remains a topic of current investigation even for the simplest architectures, due to the interrelated influence of spin, electronic and nuclear factors. ${ }^{55}$ As pointed out above, the two dyads belong to the family of "weakly-coupled" systems and only differ through the nature of their respective linkers. It should be recalled here that the $\mathrm{Ru}-\mathrm{Co}$ distances in the respective ground states are very similar. Moreover, the energy separation $\Delta E$ between the ground-state and the relaxed chargeseparated state of $\left[\mathbf{R u}^{\mathbf{I I}} \sim \mathbf{C} \mathbf{o}^{\mathbf{I I I}}\right]$ and $\left[\mathbf{R \mathbf { u } ^ { \mathrm { II } }}=\mathbf{C o} \mathbf{}^{\mathrm{III}}\right]$ are very close as well $(1.089 \mathrm{eV}$ and $1.115 \mathrm{eV}$ respectively). Therefore, the variations in photoinduced electron transfer rates can be ascribed to the physicochemical properties of the two bridges.

Fig. 10 displays the kinetics acquired at $7720 \mathrm{eV}$ (feature $\mathrm{A}^{\prime}$ on Fig. 9a) for $\left[\mathbf{R u}^{\text {II }} \sim \mathbf{C o}^{\text {III }}\right]$ (green dots) and $\left[\mathbf{R u}^{\mathbf{I I}}=\mathbf{C o}^{\text {III }}\right]$ (red dots). They monitor the formation of the charge separated state and its decay through thermally-induced charge 


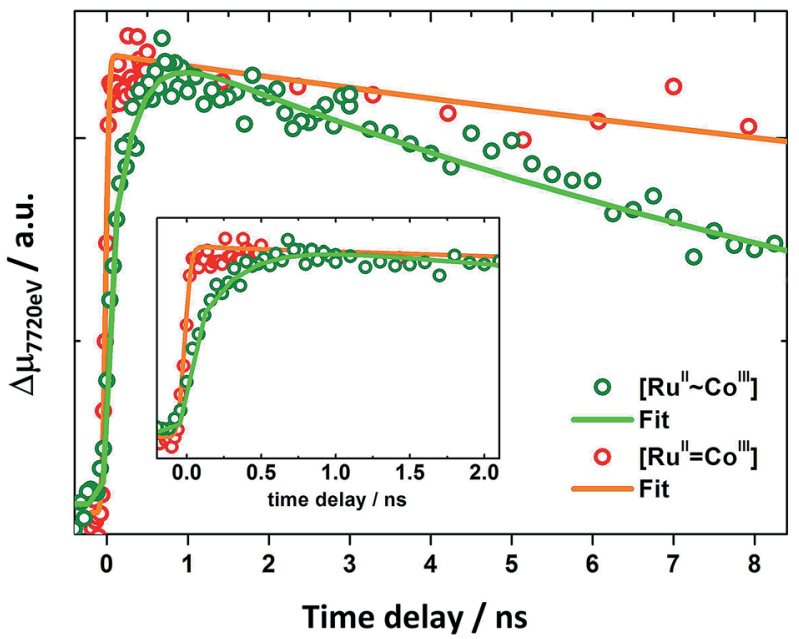

Fig. 10 Kinetics acquired at $7720 \mathrm{eV}$ as a function of optical pump-X-ray probe time delay

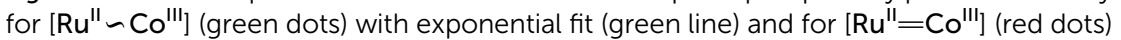
with exponential fit (orange line). The inset zooms in on the early time delays. The excitation wavelength was $527 \mathrm{~nm}$ for $\left[\mathrm{Ru}^{\prime \prime} \sim \mathrm{Co}^{\prime \prime \prime}\right]$ and $\left[\mathrm{Ru}^{\prime \prime}=\mathrm{Co}^{\mathrm{III}}\right]$.

recombination. The characteristic time constant of combined charge separation and spin-state transition is $\sim 330$ ps in $\left[\mathbf{R u}^{\mathbf{I I}} \sim \mathbf{C o}^{\mathbf{I I I}}\right]$ from optical (Fig. 6a and b, $351 \mathrm{~nm}$ excitation) and $\sim 250 \mathrm{ps}$ from the X-ray measurements (green line, Fig. 10, $527 \mathrm{~nm}$ excitation). For $\left[\mathbf{R u}^{\mathrm{II}}=\mathbf{C} \mathbf{C o}^{\mathrm{III}}\right]$ it is only $\sim 1$ ps (Fig. 7a and b), and it appears as a quasi-instantaneous rise of the transient X-ray signal in Fig. 10, owing to the $\sim 80$ ps duration of the X-ray pulse. Examining the frontier orbitals obtained from the DFT optimization shown in Fig. 11a and 12a confirms that no electron delocalization onto the alkyl chain should take place in photoexcited $\left[\mathbf{R u}^{\mathbf{I I}} \sim\right]$ and $\left[\mathbf{R u}^{\mathbf{I I}} \sim \mathbf{C o}^{\mathbf{I I I}}\right]$. On the other hand, for photoexcited $\left[\mathbf{R u}^{\mathbf{I I}}=\mathbf{C o}^{\mathbf{I I I}}\right]$, the spectral signature of electron localization onto the central part of the tpphz bridge is
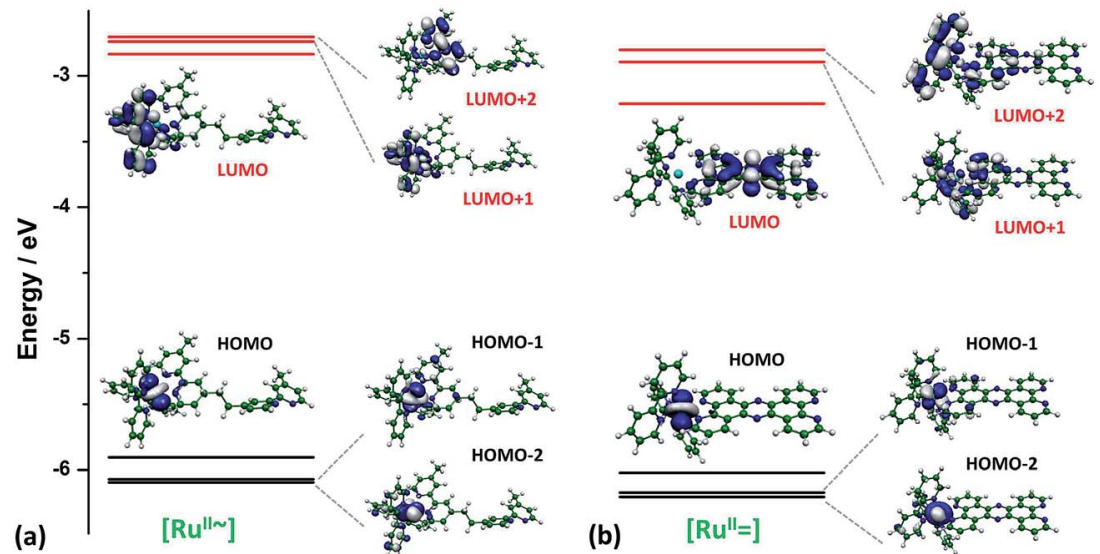

LUMO+1

Fig. 11 Frontier orbitals from DFT optimization for $\left[\mathrm{Ru}^{\prime \prime} \backsim\right]$ and $\left[\mathrm{Ru}^{\prime \prime}=\right]$ in $\mathrm{MeCN}$. 


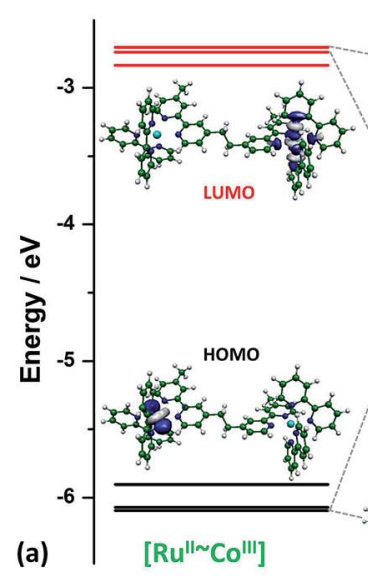

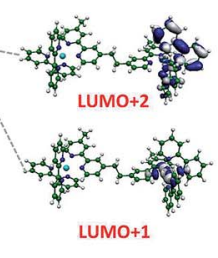

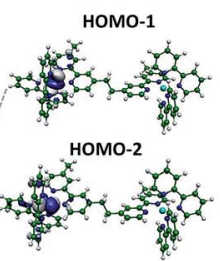

Fig. 12 Frontier orbitals from DFT optimization for $\left[\mathrm{Ru}^{\prime \prime} \sim \mathrm{Co}^{\prime \prime \prime}\right]$ and $\left[\mathrm{Ru}^{\prime \prime}=\mathrm{Co} \mathrm{O}^{\prime \prime \prime}\right]$ in $\mathrm{MeCN}$.

clearly observed in the UV-vis range (Fig. 7a). This transient state could be identified with the LUMO of $\left[\mathbf{R u}{ }^{\mathbf{I I}}=\right]$ (Fig. 12a) and the LUMO +2 of $\left[\mathbf{R u}^{\mathbf{I I}}=\mathbf{C o}^{\mathbf{I I}}\right]$ (Fig. 12b). It should be noted that when the $\left[\mathbf{R u}^{\mathbf{I I}}=\mathbf{C o} \mathbf{}^{\mathrm{III}}\right]$ dyad is excited in the red wing of its optical absorption band, the competing formation of reduced bpy is minimal. The extensive delocalization onto the $\pi$ system also lowers the reorganization energy of the forward electron transfer $\mathrm{Ru} \rightarrow$ tpphz, allowing this step to proceed at the maximal rate available from the driving force. ${ }^{56}$ As such, the subpicosecond effective reduction of the pyrazine part of the linker can then be viewed as an example of quasi-optimal matching between donor and bridge energy levels.

While the time constant of charge recombination is $\sim 45 \pm 2 \mathrm{~ns}$ in $\left[\mathbf{R u} \mathbf{I I}^{\mathbf{I I}}=\mathbf{C o} \mathbf{o}^{\mathbf{I I I}}\right]$ (red line, Fig. 10), ${ }^{29}$ it is only $\sim 13.4 \pm 0.4 \mathrm{~ns}$ in $\left[\mathbf{R u}^{\mathbf{I I}} \sim \mathbf{C o}^{\mathbf{I I I}}\right]$ (green line, Fig. 10). Considering the similarities in $\Delta E$, in structural reorganization around the $\mathrm{Ru}^{\mathrm{III}}$ and $\mathrm{Co}^{\mathrm{II}}$ centres, and in change of spin-multiplicities for the two dyads, the contrast in rates of backward electron transfer must be of conformational origin, possibly involving the first solvation shell. Unlike the rigid linker, the flexible one does not hinder close proximity between the $\mathrm{Ru}^{\mathrm{III}}$ and the $\mathrm{Co}^{\mathrm{II}}$ moieties through fluctuations, so that the recombination is more rapid.

A large distance between donor and acceptor is evidently beneficial to retard charge recombination. However, the exponential fall-off of the electronic coupling with this parameter ${ }^{55}$ is usually detrimental to the efficiency of charge separation. The rigid architecture of $\left[\mathbf{R u}^{\mathrm{II}}=\mathbf{C o}^{\mathrm{III}}\right]$ concurrently assists the extremely fast charge separation through the direct involvement of energy levels localized on the bridge, and it slows down the charge recombination by locking relative distance and orientation. Overall, this favours the high-yield formation of the photoinduced species that could be used in subsequent chemical reactions. To summarize, the present work illustrates how combining the information extracted from ultrafast optical and X-ray spectroscopies with DFT modelling can deliver a complete view into the process of charge separation and recombination in two donor-bridge-acceptor systems. This comparative study demonstrates that the long-standing problem of delineating the spin, electronic and geometric 
contributions critical to the electron transfer rates in rationally-modified molecular architectures can now be addressed with unprecedented detail.

\subsection{Implications for the study of intramolecular photochemical devices}

Maximizing the yields of long-lived charge separated species constitutes a primary goal in the optimization of molecular devices driven by photoinduced electron transfer. As a first step, it is necessary to implement panchromatic harvesting of sunlight. This can be accomplished by adding various chemical substituents to the ligands, and by packing the heteroleptic complexes into multichromophoric antennas whose cumulated absorbance matches the solar spectrum. However, these systems usually suffer from annihilation, trapping into low-lying excited states or deactivation back to the ground state. Utilizing the bridge as an electron relay or reservoir opens new channels for an efficient relaxation of all the Franck-Condon states that are initially created by the broad range of incident wavelengths. In practice, ultrafast electronic localization onto the linker in the donor-bridge unit has been unambiguously correlated to the operando performances of several intramolecular photocatalysts. ${ }^{\mathbf{9} 57}$ Characterizing the directionality of energy and electron transfer across the bridge-acceptor unit remains difficult when competing optically-bright and optically-dark (i.e. without distinctive spectral fingerprint in the UV-vis region) pathways are allowed. An exhaustive and quantitative tracking of all the rates with element and spin sensitivity can deliver a comprehensive description of these processes. To this end, the present study raises the important question of how to experimentally differentiate a formally oxidized centre $\left(\mathrm{M}^{+}-\mathrm{L}\right)$ from an $\mathrm{MLCT}\left(\mathrm{M}^{+}-\mathrm{L}^{-}\right)$state, or a formally reduced center $\left(\mathrm{M}^{-}-\mathrm{L}\right)$ from a LMCT $\left(\mathrm{M}^{-}-\mathrm{L}^{+}\right)$state, when non-innocent ligands render the site of the redox process elusive ${ }^{58}$ or when the species are optically-dark and the local structures are only slightly modified.$^{59}$ Non-emitting intermediate states are common occurrences when the linker is an extended planar aromatic conjugated system (e.g. tpphz). As exemplified above, XAS at the $\mathrm{Ru} \mathrm{K}$ edge could not readily discriminate between $\mathrm{Ru}^{\mathrm{III}}(\mathrm{bpy})^{-}(\mathrm{bpy})_{2}$ and $\mathrm{Ru}^{\mathrm{III}}(\mathrm{bpy})_{3}$, with the signal to noise ratio that was attainable at the time of the experiments. Likewise, a recent study on an osmium (Os) sensitizer has demonstrated the close resemblance between the transient spectrum of the photoexcited $\mathrm{Os}^{\mathrm{II}}$ complex and the one of the fully oxidized Os ${ }^{\mathrm{III}}$ complex. $^{60}$ Similar difficulties can be expected for $\mathrm{Pt}^{\mathrm{II}}$ and $\mathrm{Pd}^{\mathrm{II}}$ based acceptor centres of hydrogen-evolving photocatalysts. ${ }^{61,62}$ A careful calibration of the edge shift as a function of oxidation state for analogous bonding environment in model complexes, along with detailed DFT calculations, will be necessary to fully utilize the XANES sensitivity.

As a second step, a systematic application of the methodology outlined in this work may contribute to identifying the coupled spin, electronic and geometric factors that jointly promote ultrafast electronic localization and long-lived charge separation. The combination of ultrafast techniques supported by DFT and MD modelling can clearly deliver unique diagnostics about the atomic rearrangements and the evolution of the chemical bonds that are essential to stability and activity, e.g. sensitizer self-oxidation, ligand dissociation or halogen elimination. A large research effort is currently targeting the design of novel ligands that can stabilize energy-rich intermediates capable of driving chemical reactions. In addition, the photoinduced decomplexation of the donor-bridge-acceptor 
assemblies and the ensuing formation of metallic colloids remain to date some of the main reasons for low turnover numbers. ${ }^{61,62}$ Therefore, achieving rapid localization at a catalytic centre with a coordination sphere possessing high electron storage capacity should render the charge-separated species more robust toward multiple reductions. From the initial photoabsorption to the final fuel production, tailoring the entire functional cycle of intramolecular photocatalysts and fully-regenerative systems can now be approached within a unified framework.

\section{Conclusions}

Using a combination of ultrafast optical and X-ray techniques with DFT modelling, we have identified and resolved the light-induced electron transfer processes, along with the associated structural and spin changes that take place in two photoexcited heterobimetallic ruthenium-cobalt complexes. The results point to an active role of the covalent bridge in determining the rates of forward and backward electron transfer. Finally, this work also demonstrates the power of the methodology for advancing the understanding of how spin, electronic and structural factors ultimately govern the photoconversion performed by photochemical molecular devices and natural systems, such as photosystem II, the dynamics of electron transfer in proteins, or the long-range charge transport observed in DNA.

\section{Acknowledgements}

This project was supported by the Swedish Research Council (SEC, VS), the Crafoord Foundation (SEC), the Science Faculty at Lund University (MAX IV and ESS initiative grant to KW and VS), the European Research Council via contracts ERC-AdvG-VISCHEM-226136 (VS) and ERC-StG-259709 (MP), the Swedish Energy Administration (STEM) and the Knut\&Alice Wallenberg Foundation (VS). M. P. acknowledges support from the Lendület Program of the Hungarian Academy of Sciences (LP2013/59) and the Hungarian Scientific Research Fund (OTKA K 109257). X. Z., G. J., C. A. K. and the use of the Advanced Photon Source, an Office of Science User Facility operated for DOE Office of Science by Argonne National Laboratory, were supported by the U.S. DOE under Contract No. DE-AC0206CH11357. Contributions from R. M. C. Rodriguez and Dr C. J. Wallentin to early synthesis work are gratefully acknowledged. We thank Prof L. X. Chen and her group for providing the $\mathrm{Nd}$ :YLF regenerative amplifier laser.

\section{Notes and references}

1 T. R. Cook, D. K. Dogutan, S. Y. Reece, Y. Surendranath, T. S. Teets and D. G. Nocera, Chem. Rev., 2010, 110, 6474.

2 N. S. Lewis and D. G. Nocera, Proc. Natl. Acad. Sci. U. S. A., 2006, 103, 15729.

3 N. Amaroli and V. Balzani, Angew. Chem., Int. Ed., 2007, 46, 52.

4 R. Hill and P. R. A. Rich, Proc. Natl. Acad. Sci. U. S. A., 1983, 80, 978.

5 L. Duan, F. Bozoglian, S. Mandal, B. Stewart, T. Privalov, A. Llobet and L. Sun, Nat. Chem., 2012, 4, 418. 
6 A. M. Kluwer, R. Kapre, F. Hartl, M. Lutz, A. L. Spek, A. M. Brouwer, P. W. N. M. van Leeuwen and J. N. H. Reek, Proc. Natl. Acad. Sci. U. S. A., 2009, 106, 10460.

7 M. R. Wasielewki, Chem. Rev., 1992, 92, 435.

8 M. J. Rosker, M. Dantus and A. Zewail, Science, 1988, 241, 1200.

9 S. Tschierlei, M. Karnahl, M. Presselt, B. Dietzek, J. Guthmuller, L. Gonzalez, M. Schmitt, S. Rau and J. Popp, Angew. Chem., Int. Ed., 2010, 49, 3981.

10 S. Tschierlei, M. Presselt, C. Kuhnt, A. Yartsev, T. Pascher, V. Sundstrom, M. Karnahl, M. Schwalbe, B. Schaefer, S. Rau, M. Schmitt, B. Dietzek and J. Popp, Chem.-Eur. J., 2009, 15, 7678.

11 P. Hamm, M. Zurek, W. Mantele, M. Meyer, H. Scheer and W. Zinth, Proc. Natl. Acad. Sci. U. S. A., 1995, 92, 1826.

12 V. Lehtovuori, J. Aumananen, P. Myllyperko, M. Rini, E. T. Nibbering and J. Korppi-Tommola, J. Phys. Chem. A, 2004, 108, 1644.

13 V. Lehtovuori, P. Myllyperko, J. Linnanto, C. Manzoni, D. Polli, G. Cerullo, M. Haukka and J. Korppi-Tommola, J. Phys. Chem. B, 2005, 109, 17538.

14 M. S. Lynch, B. E. van Kuiken, S. L. Daifuku and M. Khalil, J. Phys. Chem. Lett., 2011, 2, 2252.

15 T. L. Courtney, Z. W. Fox, L. Estergreen and M. Khalil, J. Phys. Chem. Lett., 2015, 6, 1286.

16 M. S. Lynch, M. Cheng, B. E. van Kuiken and M. Khalil, J. Am. Chem. Soc., 2011, 133, 5255.

17 L. X. Chen, W. J. H. Jager, G. Jennings, D. J. Gosztola, A. Munkholm and J. P. Hessler, Science, 2001, 292, 262.

18 C. Bressler, C. Milne, V.-T. Pham, A. ElNahhas, M. van der Veen, W. Gawelda, S. Johnson, P. Beaud, D. Grolimund, M. Kaiser, C. N. Borca, G. Ingold, R. Abela and M. Chergui, Science, 2009, 323, 489.

19 L. X. Chen and X. Zhang, J. Phys. Chem. Lett., 2013, 4, 4000.

20 L. X. Chen, X. Zhang and M. L. Shelby, Chem. Sci., 2014, 5, 4136.

21 A. M. March, A. B. Stickrath, G. Doumy, E. P. Kanter, B. Krassig, S. H. Southworth, K. Attenkofer, C. A. Kurtz, L. X. Chen and L. Young, Rev. Sci. Instrum., 2011, 82, 073110.

22 C. J. Milne, T. J. Penfold and M. A. Chergui, Coord. Chem. Rev., 2014, 277, 44.

23 M. Chollet, R. Alonso-Mori, M. Cammarata, D. Damiani, J. Defever, J. T. Delor, Y. Feng, J. M. Glownia, J. B. Langton, S. Nelson, K. Ramsey, A. Robert, M. Sikorski, S. Song, D. Stefanescu, V. Srinivasan, D. Zhu, H. T. Lemke and D. M. Fritz, J. Synchrotron Radiat., 2015, 22, 503.

24 H. T. Lemke, C. Bressler, L. X. Chen, D. M. Fritz, K. J. Gaffney, A. Galler, W. Gawelda, K. Haldrup, R. W. Hartsock, H. Ihee, J. Kim, K. H. Kim, J. H. Lee, M. M. Nielsen, A. B. Stickrath, W. Zhang, D. Zhu and M. Cammarata, J. Phys. Chem. A, 2012, 117, 735.

25 T. Lee, Y. Jiang, C. G. Rose-Petruck and F. Benesch, J. Chem. Phys., 2005, 122, 084506.

26 J. Chen and P. M. Rentzepis, J. Phys. Chem. Lett., 2014, 5, 225.

27 J. Chen, H. Chang, I. V. Tomov, X. Ding and P. M. Rentzepis, Proc. Natl. Acad. Sci. U. S. A., 2008, 105, 15235.

28 W. K. Chen, J. Chen and P. M. Rentzepis, J. Phys. Chem. B, 2013, 117, 4332.

29 F. Benesch, T. Lee, Y. Jiang and C. G. Rose-Petruck, Opt. Lett., 2004, 29, 1028. 
30 Z. H. Loh, M. Khalil, R. E. Correa and S. R. Leone, Rev. Sci. Instrum., 2008, 79, 073101.

31 X. Song, Y. Lei, S. van Wallendal, M. W. Perkovic, D. C. Jackman, J. F. Endicott and D. P. Rillema, J. Phys. Chem., 1993, 97, 3225.

32 H. Toreida, K. Nozaki, A. Yoshimura and T. Ohno, J. Phys. Chem. A, 2004, 108, 4819.

33 C. Michael Elliott, R. A. Freitag and D. D. Blaney, J. Am. Chem. Soc., 1985, 107, 4647.

34 L. Sun, H. Berglund, R. Davydov, T. Norrby, L. Hammarström, P. Korall, A. Börje, C. Philouze, K. Berg, A. Tran, M. Andersson, G. Stenhagen, J. Mårtensson, M. Almgren, S. Styring and B. Åkermark, J. Am. Chem. Soc., 1997, 119, 6996.

35 B. P. Sullivan, D. J. Salmon and T. J. Meyer, Inorg. Chem., 1978, 17, 3334-3341.

36 S. E. Canton, X. Zhang, J. Zhang, T. B. van Driel, K. S. Kjaer, K. Haldrup, P. Chabera, T. Harlang, K. Suarez-Alcantara, Y. Liu, J. Pérez, A. Bordage, M. Pápai, G. Vankó, G. Jennings, C. A. Kurtz, M. Rovezzi, P. Glatzel, G. Smolentsev, J. Uhlig, A. O. Dohn, M. Christensen, A. Galler, W. Gawelda, C. Bressler, H. T. Lemke, K. B. Møller, M. M. Nielsen, R. Lomoth, K. Wärnmark and V. Sundström, J. Phys. Chem. Lett., 2013, 4, 1972.

37 A. Corani, A. Pezzella, T. Pascher, T. Gustavsson, D. Markovitsi, A. Huisjer, M. d'Ischia and V. Sundström, J. Phys. Chem. Lett., 2013, 4, 1383.

38 M. Jäger, A. Smeigh, F. Lombeck, H. Görls, J.-P. Collin, J.-P. Sauvage, L. Hammarström and O. Johansson, Inorg. Chem., 2010, 49, 374.

39 F. Neese, ORCA, version 2.8, Max-Planck-Institut für Bioanorganische Chemie, Mülheim an der Ruhr, Germany, 2010.

40 (a) H. Paulsen and A. X. Trautwein, Top. Curr. Chem., 2004, 235, 197; (b) A. Hauser, C. Enachescu, M. Lawson Daku, A. Vargas and N. Amstutz Coord, Chem. Rev., 2006, 250, 1642; (c) A. Vargas, M. Zerara, E. Krause, A. Hauser and L. M. L. Daku, J. Chem. Theory Comput., 2006, 2, 1342-1359; (d) Y. Shiota, D. Sato, G. Juhasz and K. Yoshizawa, J. Phys. Chem. A, 2010, 114, 5862-5869; (e) M. Pápai, G. Vankó, C. de Graaf and T. Rozgonyi, J. Chem. Theory Comput., 2013, 9, 509.

41 A. Klamt and G. J. Schüürmann, J. Chem. Soc., Perkin Trans. 2, 1993, 799.

42 A. L. Fetter and J. D. Walecka, Quantum Theory of Many Particle Systems, MCGraw-Hill, New York, 1971, ch. 15, p. 565.

43 N. H. Damrauer, G. Cerullo, A. Yeh, T. R. Boussie, C. V. Shank and J. K. McCusker, Science, 1997, 275, 54.

44 L. Flamigni, S. Encinas, F. Barigelletti, F. M. MacDonnell, K. J. Kim, F. Puntoriero and S. Campagna, Chem. Commun., 2000, 1185.

45 R. C. Young, T. J. Meyer and D. G. Whitten, J. Am. Chem. Soc., 1976, 98, 286.

46 J. Bolger, A. Gourdon, H. Ishow and J.-P. Launay, Inorg. Chem., 1996, 35, 2937.

47 C. Chiorboli, M. A. J. Rodgers and F. Scandola, J. Am. Chem. Soc., 2003, 125, 483.

48 S. E. Canton, K. S. Kjaer, G. Vanko, T. B. van Driel, S. Adachi, A. Bordage, C. Bressler, P. Chabera, M. Christensen, A. O. Dohn, A. Galler, W. Gawelda, D. Gosztola, K. Haldrup, T. Harlang, Y. Liu, K. B. Møller, Z. Németh, S. Nozawa, M. Pápai, T. Sato, T. Sato, K. Suarez-Alcantara, T. Togashi, K. Tono, J. Uhlig, D. A. Vithanage, K. Wärnmarck, V. Sundström and M. M. Nielsen, Nat. Commun., 2015, 6, 6359. 
49 D. Cabaret, A. Bordage, A. Juhin, M. Arfaoui and E. Gaudry, Phys. Chem. Chem. Phys., 2010, 12, 5619.

50 C. R. Natoli, Near Edge Structure III, Springer Proc. Phys., 1984, 2, 38.

51 I. Krivokapic, M. Zerera, M. L. Daku, A. Vargas and A. Hauser, Coord. Chem. Rev., 2007, 251, 364.

52 R. Sieber, S. Descurtins, H. Stoeckli-Evans, C. Wilson, D. Yufit, J. A. K. Howard, S. C. Capelli and A. Hauser, Chem.-Eur. J., 2000, 6, 361.

53 W. Liu, W. Xu, J.-L. Lin and H.-Z. Xie, Acta Crystallogr., Sect. E: Struct. Rep. Online, 2008, 64, M1586-U987.

54 M. Du, X.-J. Zhao and H. Cai, Z. Kristallogr., 2004, 219, 463.

55 H. B. Gray and J. R. Winkler, Proc. Natl. Acad. Sci. U. S. A., 2005, 102, 3534.

56 H. A. Meylemans, C. F. Lei and N. H. Damrauer, Inorg. Chem., 2008, 47, 4060.

57 H. Nitadori, T. Takahashi, A. Inagaki and M. Akita, Inorg. Chem., 2012, 51, 51.

58 W. Kaim and G. K. Lahiri, Angew. Chem., Int. Ed., 2007, 46, 1778.

59 M. Elvington, J. Brown, S. M. Arachchige and K. J. Brewer, J. Am. Chem. Soc., 2007, 129, 10644.

60 X. Zhang, S. E. Canton, G. Smolentsev, C.-J. Wallentin, Y. Liu, Q. Kong, K. Attenkofer, A. B. Stickrath, M. W. Mara, L. X. Chen, K. Wärnmark and V. Sundström, J. Am. Chem. Soc., 2014, 136, 8804.

61 P. Lei, M. Hedlund, R. Lomoth, H. Rensmo, O. Johansson and L. Hammarström, J. Am. Chem. Soc., 2006, 128, 4927.

62 H. Ozawa, M. Haga and K. Sakai, J. Am. Chem. Soc., 2006, 128, 4926. 